\title{
Dexmedetomidine in Traumatic Brain Injury, Why Not?
}

\author{
Elmansoury Michael R* \\ Fujiarah Hospital, UAE
}

Submission: February 23, 2017; Published: February 23, 2017

*Corresponding author: Elmansoury Michael R, Fujairah hospital, PO box. 9317 Fujerah, UAE, Email: mick_bengawy@hotmail.com

\section{Editorial}

Dexmedetomidine is an alpha-2 adrenoreceptor agonist with sedative, analgesic and anxiolytic properties. Since its release in the US market in late 1999, it has gained remarkable attention in the adult, pediatric and geriatric populations, predominantly because of its minimal respiratory depression. However, beyond its well-known properties, dexmedetomidine has recently been investigated for its potential in many other clinical scenarios, including neuroprotection, cardioprotection and renoprotection, with promising results [1].

Traumatic brain injuries, intracranial hemorrhage, intracranial malignancies, stroke, subarachnoid hemorrhage, and other conditions can precipitate the development of Cerebral edema and intracranial hypertension. Management options for intracranial hypertension include elevating the head of bed, normoventilation, eunatremia, pain control, reduction of noxious stimuli, and prevention of fever, hypoxemia, and hypotension. Sedation and analgesia with continuous infusions are considered first-line therapies to control intracranial hypertension in comatose patients who are intubated. The theoretical mechanism of continuous IV sedatives for ICP control is a safe reduction in cerebral blood flow and hence blood volume by reducing cerebral metabolic demand. Dexmedetomidine acts as a potent and specific alpha- 2 adrenergic receptor agonist; it is unique in providing sedative-analgesic and anxiolytic effects without causing respiratory depression [2].

It has been hypothesized that global and focal cerebral ischemic events can be attenuated by the use of alpha- 2 adrenoreceptor agonists. Catecholamine release is likely a factor contributing to injury. Catecholamines can potentially exacerbate neuronal injury by multiple mechanisms (catecholamines mediated increases in sensitivity to neurotransmitters such as glutamate; increased neuronal activity leading to expression of catabolic enzymes and possibly cell death due to excessive excitation; direct toxic effect of catecholamines on neurons; free radical formation) [3].
However, there is a significant and unresolved issue with respect to the safety and suitability of dexmedetomidine for use in patients who have or who are at risk for neurologic injuries. That issue is the matter of the uncertainty as to the effect of dexmedetomidine on the ratio of cerebral oxygen supply to cerebral oxygen demand (the ratio of cerebral blood flow CBF to cerebral metabolic rate CMR). The concern arises because the limited existing body of information suggests that dexmedetomidine might result in a reduction of the $\mathrm{CBF} / \mathrm{CMR}$ ratio. The available information indicates that dexmedetomidine causes a reduction of CBF in humans. The effect of dexmedetomidine on CMR is less well documented [4].

Kendra J [5] and his colleagues suggested that Dexmedetomidine may avoid increases in the need for rescue therapy when used as an adjunctive treatment of refractory intracranial hypertension without compromising hemodynamics. He did his study on 23 patients undergo refractory intracranial hypertension. The primary objective of this review was to determine the change in quantified need for rescue therapy (hyperosmolar boluses and extraventricular drain [EVD] drainages). He used a dose of infusion $0.2-0.7 \mathrm{mcg} /$ $\mathrm{kg}$ /hours [5].

Ji-shen LUO [6] and his colleagues found that Dexmedetomidine could alleviate the stress as result of moderate and severe traumatic brain injury, and its anti-stress, and sedative effect was similar to those of propofol, but it's necessary to monitor the blood pressure. He did his study on 90 patients. He used a dose of bolus $0.5-1 \mathrm{mcg} / \mathrm{kg}$ on 30 minutes then infusion $0.2-0.6 \mathrm{mcg} / \mathrm{kg} /$ hours for $24 \mathrm{hrs}$ [6].

Pajoumand M [7] and his colleagues cautioned that Dexmedetomidine was found to be associated with significantly more hypotension. He did his study on 198 patients. On the other hand, Hao J [8] and his colleagues results coincide with The sedation efficacy of DEX was superior to propofol in moderate and severe TBI, and was able to control excessive stress response 
after TBI better, and with more effect on blood pressure. He used the same protocol used by Ji-shen LUO [6].

Nakano T [9] and his colleagues suggested that Hypertension following the administration of high-dose dexmedetomidine is associated with cerebral hypoperfusion and the exacerbation of ischemic brain injury, possibly through alpha-2-induced cerebral vasoconstriction. He did his research on rat model. However Manhe Zhang [10] and his colleagues found that the mechanism by which dexmedetomidine reduces TBI is related to inhibition of autophagy in the hippocampal neurons of rats.

From all the above, I agreed with authors that Dexmedetomidine have a leading effect on reducing stress related secondary brain injury. However, Other beneficial effects in reducing apoptosis, and $\mathrm{CBF} / \mathrm{CMR}$ ratio have limited existing evidences.

\section{Conclusion}

In Conclusion, Dexmedetomidine has a promising role in traumatic brain injury management, however hypotension must be avoided. Therefore, larger studies are needed to identify the role of Dexmedetomidine in traumatic brain injury and the effect on cerebral metabolic rate

\section{References}

1. Chrysostomou C, Schmitt CG (2008) Dexmedetomidine: sedation, analgesia and beyond. Expert Opin Drug MetabToxicol 4(5): 619-27.

2. Flower 0, Hellings S (2012) Sedation in traumatic brain injury. Emerg Med Int 2012: 1-11.
3. Adam Schwarz, Bobby Nossaman, Dominic Carollo, Usha Ramadhyani (2013) Dexmedetomidine for Neurosurgical Procedures. Current Anesthesiology Reports 3(3): 205-209.

4. Drummond JC, Dao AV, Roth DM, Cheng CR, Atwater BI, et al. (2008) Effect of dexmedetomidine on cerebral blood flow velocity, cerebral metabolic rate, and carbon dioxide response in normal humans. Anesthesiology 108(2): 225-232.

5.Schomer KJ, Sebat CM, Adams JY, Duby JJ, Shahlaie K (2017) Dexmedetomidine for Refractory Intracranial Hypertension. J Intensive Care Med.

6. Ji-shen LUO, Jiang HAO, Yi HE, Qi WENG, Jun LIU, et al. (2013) Role of dexmedetomidine in stress control in traumatic brain injury and its influence on neuroendocrine system. Medical Journal of Chinese People's Liberation Army 38(11).

7. Pajoumand M, Kufera JA, Bonds BW, Devabhakthuni S, Boswell S, Hesselton K, Scalea TM, Stein DM.Dexmedetomidine as an adjunct for sedation in patients with traumatic brain injury.J Trauma Acute Care Surg. 2016 Aug;81(2):345-51.

8. Hao J, Luo JS, Weng Q He Y, Liu J, et al. (2013) Effects of Dexmedetomidine on sedation and $\beta$-endorphin in traumatic brain injury: a comparative study with propofol. Zhonghua Wei Zhong Bing Ji Jiu Yi Xue 25(6): 373376.

9. Nakano T, Okamoto H (2009) Dexmedetomidine-induced cerebral hypoperfusion exacerbates ischemic brain injury in rats. J Anesth 23(3): 378-384.

10. Manhe Zhang, Xiumin Zhou, Yanjie Xing, Dong Chen, Shidong Kang, et al. (2015) Effect of dexmedetomidine on autophagy in hippocampal neurons of rats with traumatic brain injury. Chinese Journal of Anesthesiology 35(3): 373-376.
Your next submission with Juniper Publishers will reach you the below assets

- Quality Editorial service

- Swift Peer Review

- Reprints availability

- E-prints Service

- Manuscript Podcast for convenient understanding

- Global attainment for your research

- Manuscript accessibility in different formats ( Pdf, E-pub, Full Text, Audio)

- Unceasing customer service

Track the below URL for one-step submission https://juniperpublishers.com/online-submission.php 